\title{
Some results of tectonomagnetic monitoring in the epicentral zone of the M7.5 Altay earthquake, September 27, 2003
}

\author{
Pyotr G. Djadkov, Oleg A. Mikheev, Maxim I. Minenko and Oleg A. Sobolev \\ Institute of Geophysics, Siberian Branch of the Russian Academy of Sciences (SB RAS), Novosibirsk, Russia
}

\begin{abstract}
We report tectonomagnetic results from the epicentral area of the 27 September $2003 M_{s}=7.5$ earthquake in the Altay mountains, southern West Siberia. The results were obtained in the first three survey campaigns in early October 2003, late November 2003, and latest May-early June 2004 using an array of one continuous-measurement station and fifteen repeated-survey sites. Changes in total geomagnetic field associated with seismic activity were mostly of regional scale and usually did not exceed $1.5 \mathrm{nT}$. The $M=4.5$ aftershock of 31 May 2004 was accompanied by an anomaly of 1-2 nT. The location of the anomaly within highly magnetic rocks can be evidence of its piezomagnetic origin.
\end{abstract}

Key words tectonomagnetic monitorng - piezomagnetic model - aftershock process - stress change

\section{Introduction}

Tectonomagnetic monitoring of ongoing geodynamic and seismic activity is based mainly on the piezomagnetic effect of rock magnetization variations caused by changes in crustal stress.

Many laboratory (e.g., Kapitsa, 1955; Nagata, 1969; Kean et al., 1976) and modeling (e.g., Stacey, 1965; Hao et al., 1982; Sasai, 1983) data show that natural processes accompanied by stress changes influence the surface geomagnetic field and can generate tectonomagnetic anomalies which are most often as low as a few nT.

Mailing address: Dr. Pyotr G. Djadkov, Institute of Geophysics, Siberian Branch of the Russian Academy of Sciences (SB RAS), Russian Federation, Koptuyga prosp. 3, 630090 Novosibirsk, Russia; e-mail: djad@uiggm.nsc.ru
Tectonomagnetic anomalies can be amplified by space variations in rock magnetization associated with static magnetic anomalies (Fotiady et al., 1969; Zlotnicki and Cornet, 1986; Dyadkov, 1987; Oshiman, 1990). More evidence on this point comes from field experiments near Lake Baikal (Dyadkov et al., 1999).

Another mechanism proposed to explain tectonomagnetic anomalies is based on the circulation of electrical currents as a result of variable potentials induced by fluids percolating through solid rocks (Mizutani et al., 1976; Zlotnicki and Le Mouel, 1990). However, the electrokinetic effects must be weaker than the piezomagnetic effects in normal geodynamic conditions (Kormiltsev and Retushniak, 1997).

Detection of low tectonomagnetic anomalies requires high-precision and stable instruments and special processing (filtering) techniques to separate the signal from noise (Davis et al., 1981; Dyadkov, 1985).

At present, tectonomagnetic monitoring has been successfully practised in many geodynamic provinces (e.g., Rikitake et al., 1980; Abdulla 


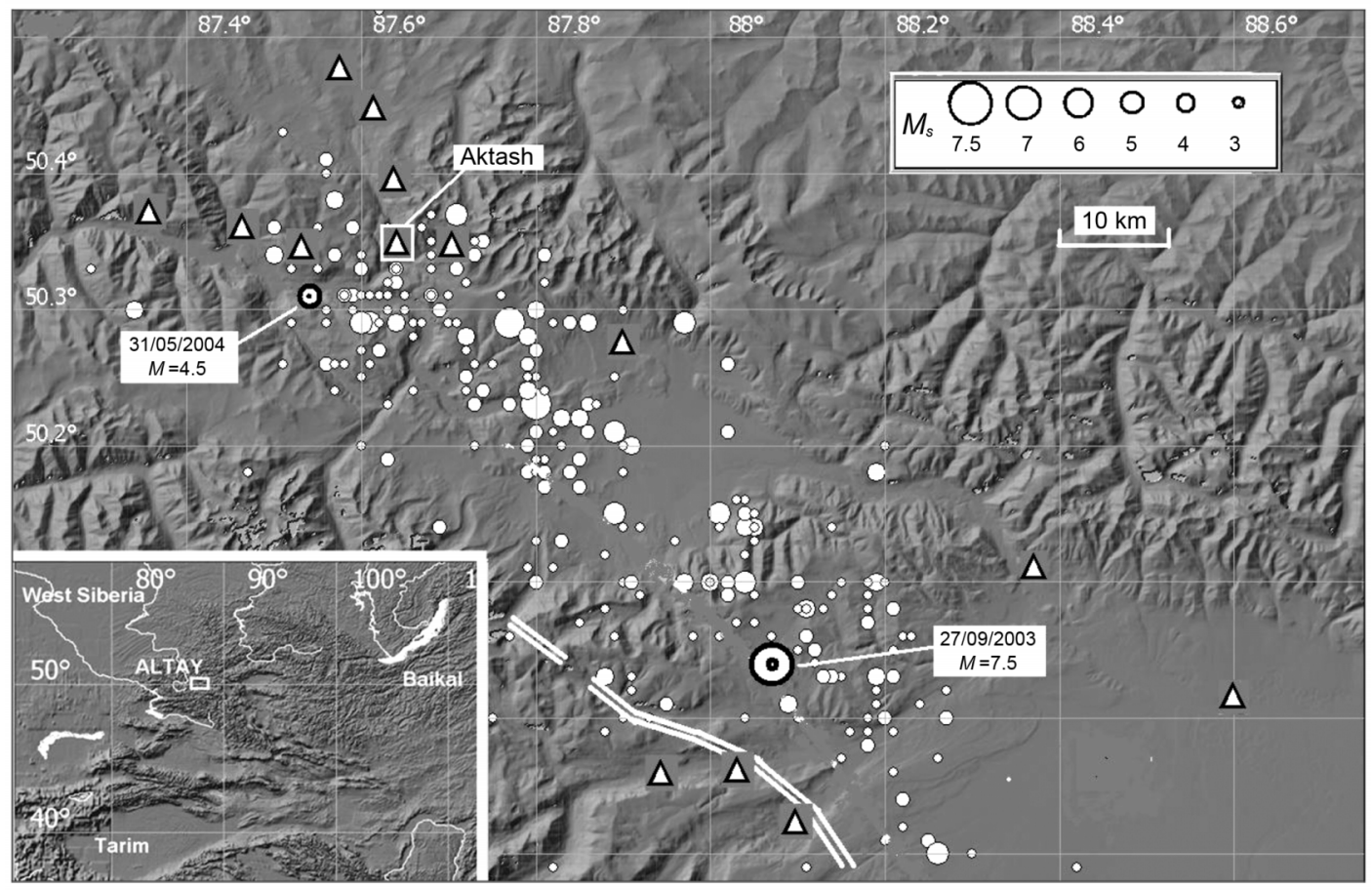

Fig. 1. Array of repeated-survey tectonomagnetic stations (triangles) and epicenters of $M>3$ aftershocks of the $M=7.5$ Altay earthquake of 27 September 2003 (circles). Triangles show repeated-survey sites and boxed triangle shows the continuous station. Double white line delineates the fault scarp produced by the Altay earthquake. Inset shows location map of study area.

bekov, 1987; Johnston, 1989; Zlotnicki and Le Mouel, 1990; Kuznetsova and Maksimchuk, 1994; Shapiro et al., 1994; Dyadkov et al., 1999; Meloni et al., 2004).

We applied the tectonomagnetic method to monitor the postseismic behavior of crustal stress in the epicentral area of a large continental earthquake. The monitoring results have essential implications for relaxation of crustal stress after a large earthquake and the physics of tectonomagnetic anomalies.

\section{Earthquake parameters and aftershocks}

The $M_{s}=7.5$ Altay earthquake occurred on 27 September 2003 in the Altay mountains in southern West Siberia (fig. 1).

The shock of 27 September 2003 came unexpectedly, though prehistoric fault scarps of large earthquakes in the region have been known to seismologists. The last large historic event in the vicinity of the Altay shock dates back to 1761 or about 250 years ago (the $M \sim 8$ Mongolian earthquake).

The Altay earthquake shows a right-lateral strike-slip mechanism (Emanov and Leskova, 2005). The slip plane strikes in the NW direction and is traceable on the surface for a distance of up to $60 \mathrm{~km}$. The depth of the main shock is $15-18 \mathrm{~km}$. Two $M_{s}=6.5$ and $M_{s}=6.9$ aftershocks followed in four days after the main shock. The total length of the aftershock zone reaches $\sim 80 \mathrm{~km}$ (fig. 1 ).

\section{Monitoring array and methods}

The monitoring array was deployed 5-8 days after the main shock, from 2 to 5 October 
2003, and included 15 repeated-survey sites and a reference station Aktash for continuous total field monitoring (fig. 1). In the period from 25 to 28 May 2004 additional repeated-survey stations (Turbaza, Medved' and Kuk-slez) were installed in the northwestern part of the aftershock area. The position of the Aktash continuous station was chosen in a site of a permanent seismic station of the regional network.

Total field intensity at the repeated-survey stations was measured by Kazgeofizpribor MM-61 proton magnetometer with a sensitivity of $0.1 \mathrm{nT}$, a long-term stability of $\sim 0.2 \mathrm{nT}$ and a thermal drift under $\sim 0.03 \mathrm{nT}$ per $10^{\circ}$.

The continuous station was equipped with Geomer MV-08 total field proton magnetometer of $0.01 \mathrm{nT}$ sensitivity, a long-term stability of $\sim 0.2 \mathrm{nT}$, and a thermal drift under $\sim 0.01 \mathrm{nT}$ per $10^{\circ}$.

In each repeated-survey site, the sensor was positioned to an accuracy of a few millimeters and then the magnetic field was measured at a sampling interval of $20 \mathrm{~s}$ in sessions of 5-10 samples each, simultaneously with sampling at the continuous station. The measurements were run normally in the night time when diurnal magnetic fluctuations are the lowest.

Note that magnetic surveys in the Altai mountains are run in favorable conditions due to the absence of cultural noise and low anomalous field in most sites.

The time-dependent transient magnetic field component due to ionosperic and magnetospheric currents was eliminated by calculating
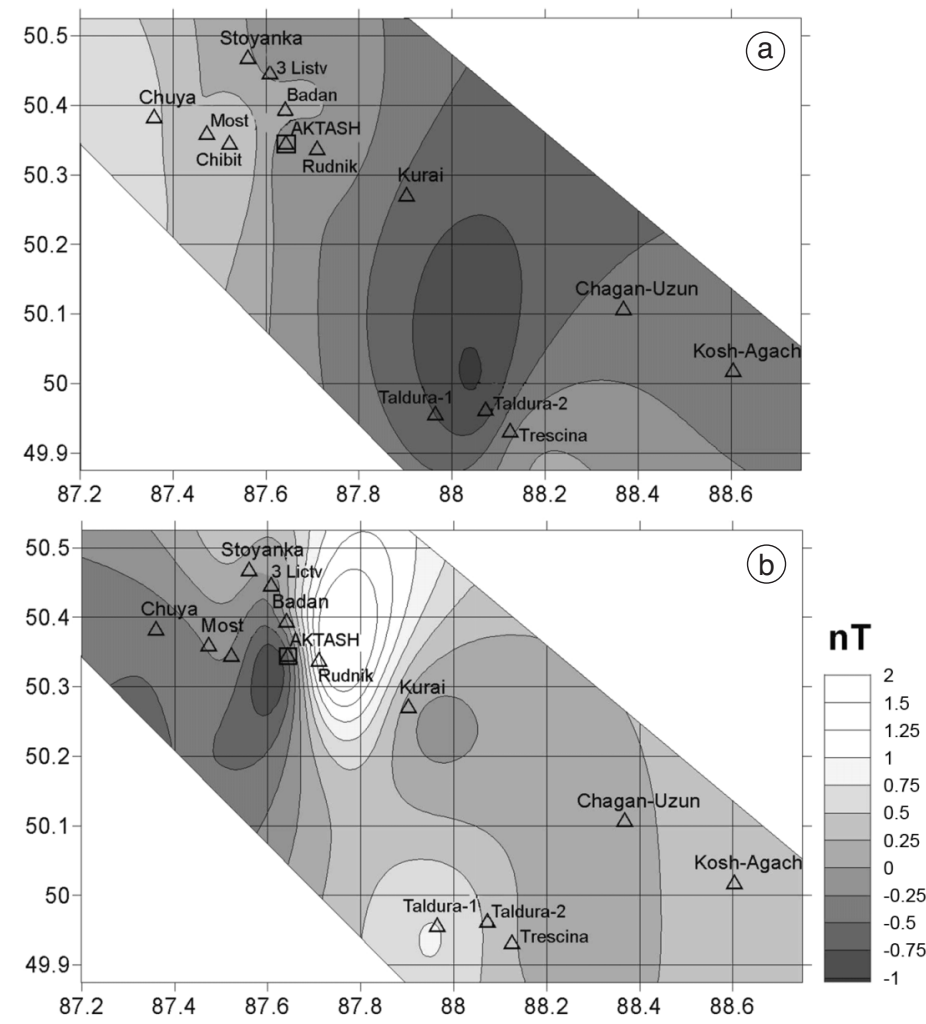

Fig. 2a,b. Total field variations in the epicenter of the main shock of 27/09/2003 a) from early October to late November 2003 and b) from late November 2003 to late May 2004. Triangles show repeated-survey sites and boxed triangle shows the continuous station. 
the difference between synchronous magnetic field readings at the repeated-survey sites and at the Aktash reference station. The standard deviation of such differences for a session of 5-10 samples was as a rule below $0.1 \mathrm{nT}$.

We estimated the space gradient of secular geomagnetic variations for the territory of our tectonomagnetic network using the International Geomagnetic Reference Field (IGRF) model (McGuire, 2004). The gradient found as the difference of values between stations of Koshagach (extreme southeastern point) and Medved' (extreme northwestern point) was negligible (within $0.03 \mathrm{nT}$ ) through 2003-2004, though this estimate appears not very reliable because of the scarcity of the network of magnetic observatories in this region of Asia.

Repeated surveys at the fifteen stations were carried out in three campaigns over the period from October 2003 to June 2004: from 2 to 5 October 2003, or 5-8 days after the main shock; from 18 to 22 November 2003, about 50 days after the main shock; and from 25 to 28 May 2004. Survey was repeated again after the $M_{s}=4.5$ aftershock of 31 May 2004 at some sites in its vicinity.

\section{Observations}

Total field changes over the period from October 2003 to November 2003. Figure 2a shows total field changes between the first and second campaigns. Differential change relative to the Aktash data was within $-1 \mathrm{nT}$ to $+0.6 \mathrm{nT}$. The strongest negative anomaly was measured in the epicenter of the main shock and positive values cluster near the northwestern termination of the aftershock area.

Total field changes over the period from November 2003 to May 2004. An anomaly up to 2 nT emerged in the northwestern part of the aftershock area (fig. 2b), with its maximum near site Rudnik. New sites of Turbaza, Medved' and Kuk-slez. were installed during the third campaign on 25-28 May 2004 and a repeated survey was planned at Rudnik and at the neighboring sites after the anomaly was detected on 2528 May 2004. However, an $M=4.5$ aftershock had occurred on 31 May 2004 before the repeated survey was set up.
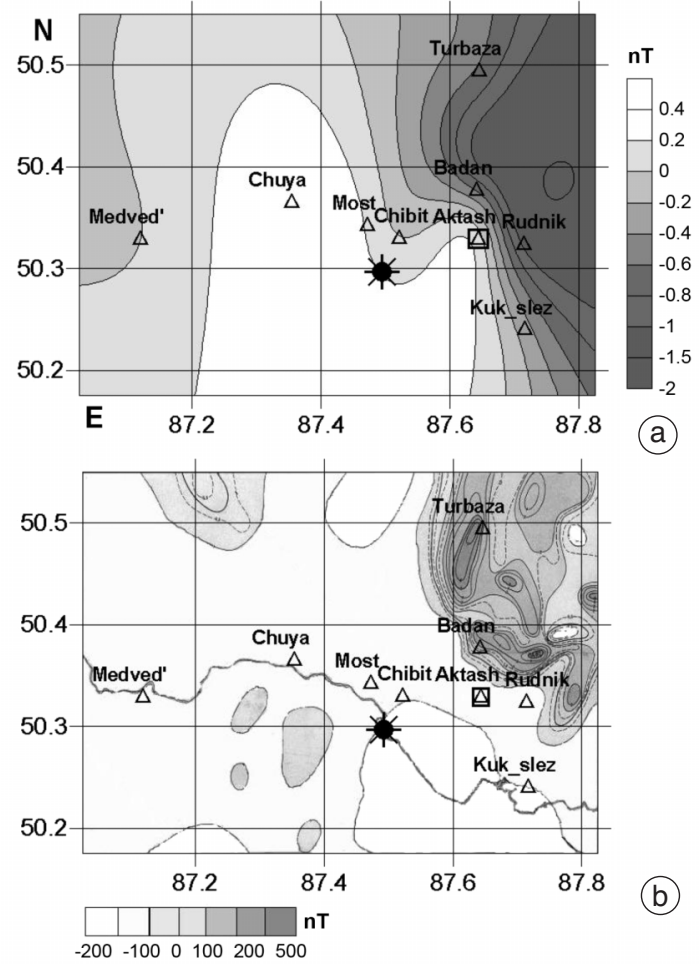

Fig. 3a,b. a) Tectonomagnetic anomaly and b) anomalous magnetic field in the epicenter area of the $M=4.5$ aftershock of 31 May 2004 (asterisk). Triangles show repeated-survey sites and boxed triangle shows the continuous station.

Total field changes associated with the 31 May 2004 aftershock. A repeated survey was set up on 2-3 June 2004 at nine sites, including the new sites of Turbaza, Medved' and Kukslez, in the region of the 31 May 2004 aftershock to detect the related anomalies. Total field intensity was monitored over a short period from latest May to earliest June 2004 and showed a prominent anomaly of $2 \mathrm{nT}$ (fig. 3a) a few kilometers northeast of the aftershock.

\section{Discussion and conclusions}

Interpretation of regional-scale magnetic variations from October to November 2003 
(fig. 2a) is challenging because rock magnetization, piezomagnetic coefficients, and the crustal structure in the central part of the region remain poorly explored. Moreover, low values of static magnetic anomalies $F_{a}$ indicate low magnetization in the upper crust. The $1 \mathrm{nT}$ negative anomaly near the main shock requires further investigation and modeling.

Anomalies of piezomagnetic origin are marked by their spatial association with static anomalies generated by highly magnetic rocks. We observed this association in the case of the tectonomagnetic anomaly related to the $M=4.5$ aftershock of 31 May 2004 (Fig. 3a,b). Stations Rudnik, Badan, and Turbaza fall within the edge of the static anomaly $F_{a}$ produced by high-magnetization rocks (see the anomalous field $F_{a}$ in fig. 3b). Thus, the aftershock-related anomaly may be a piezomagnetic one.

Stress change presumably responsible for the observed tectonomagnetic anomalies was estimated by forward modeling using a software for 3D imaging of heterogeneous magnetization and piezomagnetic patterns (Sobolev and Djadkov, 2003). Finite-element solutions for piezomagnetic anomalies were obtained based on the formalism from (Hao et al., 1982). Following Hao et al. (1982) we assumed that magnetization change in stress-normal direction is half the magnitude of change in stressparallel direction and is of the opposite sign.

The piezomagnetic anomalies associated with the magnetic field change after the 31 May 2004 aftershock were computed assuming nearly horizontal principal extension stress in the N$\mathrm{S}$ direction. We attribute this extension to the aftershock which released the regional compression stress due to the India/Eurasia collision and related northward indentation of India. An extension environment was likewise inferred from the focal mechanisms of the main shock, the largest aftershocks (Emanov and Leskova, 2005) and the aftershock of 31 May 2004 (Leskova, pers. comm.). Modeling was performed for an input magnetic susceptibility in the region of highly magnetic rocks of 0.024 SI and input piezomagnetic coefficients of $1 \times 10^{-3} \mathrm{MPa}^{-1}$. The change in horizontal stress that can generate the recorded anomalies in the input conditions is within 2-4 MPa.
Figure 4a,b presents a version of a 3D piezomagnetic model for the crustal block within the territory of fig. 3b. The anomaly-producing body (dark part of the finite-element grid in fig. 4a) has a magnetic susceptibility of 0.024 SI. It is located at depths between $1 \mathrm{~km}$ and $15 \mathrm{~km}$ and is assumed to keep its geometry invariable in the vertical dimension. The remaining part of the block is nonmagnetic (white part of the finite-element grid in fig. 4a). The components of the total field $\boldsymbol{F}$ are $55000 \mathrm{nT}(Z), 20000(X)$ and $0 \mathrm{nT}(Y)$. The change in N-S horizontal stress (uniform extension) is assumed to be $4 \mathrm{MPa}$. The calculated piezomagnetic anomaly is shown in fig. 4b.

The computed (fig. 4b) and measured (fig. 3a) features generally agree and the sites of Tur-

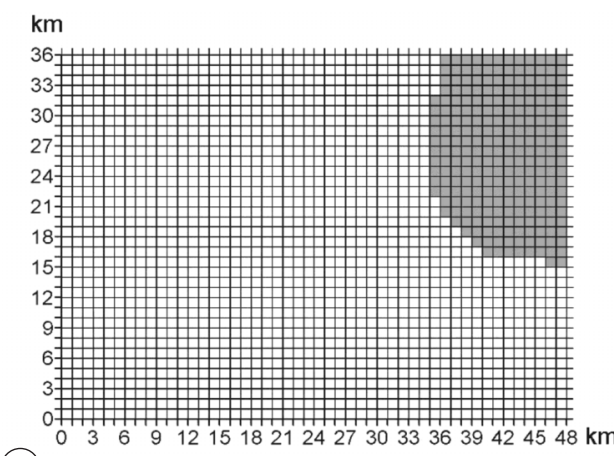

(a)

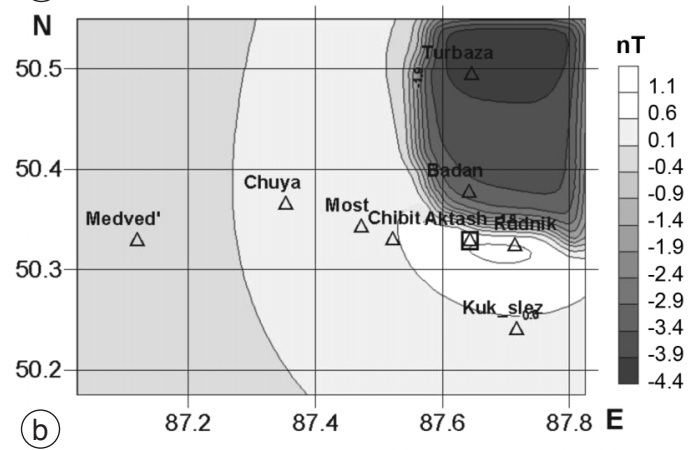

Fig. 4a,b. A version of a 3D piezomagnetic model for the crustal block within the territory of fig. 3b. Finite-element grid (a) with the anomaly-producing body of a magnetic susceptibility of 0.024 SI shown by dark and computed piezomagnetic anomaly associated with the 31 May 2004 aftershock, $M=4.5$ (b). 
baza and Badan fall into the computed anomaly, but the model predicts a positive anomaly in the Rudnik site contrary to the pattern in fig. 3a. This discrepancy may be due to a wrong assumption of the subsurface geometry of high-magnetic rocks and the too rough approximation of uniform stress change. Further improvement of the model requires including stress data based on a 3D dislocation model of the aftershock.

The piezomagnetic origin of the tectonomagnetic anomaly near the aftershock of 31 May 2004 appears less ambiguous due to the spatial association of the anomaly with highly magnetic rocks. The anomaly between October and November 2003 (fig. 2a) occurred in the zone where rocks (at least in the shallow subsurface) are low magnetic, and interpretation of its origin requires further studies.

\section{Acknowledgements}

The study was supported by grant 0305 65418 from the Russian Foundation for Basic Research, a grant from the Integration Projects $16,87,6.18$ of the Siberian Branch of the Russian Academy of Sciences and a grant for Project 3 of Program 16 of the Russian Academy of Sciences.

We greatly appreciate the constructive criticism of the reviewers Dr. J. Zlotnicki and Dr. Y. Tanaka.

\section{REFERENCES}

AbdullabeKov, K.N. (1987): Electromagnetic Phenomena in the Earth's Crust (FAN Press), 3-231.

DAVIS, P.M., D.D. JACKSON, C.A. SEARLS and R.L. McPherRON (1981): Detection of tectonomagnetic events using multichannel predictive filtering, J. Geophys. Res., 86 (B3), 1731-1737.

DYADKOV, P.G. (1985): Linearity of secondary effects of geomagnetic variations in anomalous fields in the case of modulus measurements, Sov. Geol. Geophys., 26 (4), 129-136.

DYADKOV, P.G. (1987): Linearity of secondary effects of geomagnetic variations in anomalous fields in the case of modulus measurements, Sov. Geol. Geophys., 28 (2), 65-72.

DyadKov, P.G., M.M. Mandelbaum, G.I. TatKov, V.A. Larionov, N.V. Zhirova, O.A. MikheEv, R.S. NiZAMUtDinov and G.A. ChebaKov (1999): Development of seismotectonic and preseismic processes in the cen- tral Baikal rift zone, from tectonomagnetic observations, Russ. Geol. Geophys., 40 (3), 343-355.

Emanov, A.A. and E.V. Leskova (2005): Structure of the aftershock process of the Chuya earthquake (Gorny Altai), Russ. Geol. Geophys., 46 (10), 1065-1072.

Fotiady, E.E., G.I. Karataev, V.A. Larionov and V. CheREMISIN (1969): On piezomagnetic effect of stress change influence on magnetic bodies, DAN SSSR, 187 (6), 1282-1284.

Hao, J., L.M. Hastie and F.D. Stacey (1982): Theory of the seismomagnetic effect: an assessment, Phys. Earth Planet. Inter., 28 (12), 129-140.

JoHNSTON, M.J.S. (1989): Review of magnetic and electric field effects near active faults and volcanoes in U.S.A., Phys. Earth Planet. Inter., 57, 47-63.

KAPITSA, S.P. (1955): Magnetic properties of igneous rocks under mechanic stress, Izv. AN SSSR, Ser. Geofizika, 6, 489-504.

Kean, W.F., R. Day, M. Fuller and V.A. Schmidt (1976): The effect of uniaxial compression on the initial susceptibility of rocks as a function of grain size and their constituent titanomagnetites, J. Geophys. Res., 81, 861872 .

KoRMILTSEV, V.V. and A.N. RATUSHNIAK (1997): Electric and magnetic field induced by fluids in porous solids with local heterogeneities of permeability and electric properties, Izv. RAN, Ser. Fizika Zemli, 8, 81-87.

Kuznetsova, V.G. and V.E. MAKsimchuK (1994): Tectonomagnetic investigations for study of structure and recent geodynamics of lithosphere of the Carpatian region, J. Geophys. Geodyn., 1 (1), 31-42.

McGuIRE, R. (2004): DGRF/IGRF Geomagnetic Field Model 1945-2010 and Related Parameters (avalable on line at http://nssdc.gsfc.nasa.gov/space/model/models/igrf.html).

Meloni, A., D.D. Mauro, S. LePidi, G. Mele and P. PalanGIO (2004): Tectonomagnetic and VLF electromagnetic signals in Central Italy, Ann. Geophysics, 47 (1), 29-37.

MizUTANi, H., T. IsHido, T. YoKoKURA and S. OHNISHI (1976): Electrokinetic phenomena associated with earthquakes, Geophys. Res. Lett., 3, 365-368.

NAGATA, T. (1969): Tectonomagnetism, IAGA Bull., 27, 12-43.

OSHIMAN, N. (1990): Enhancement of tectonomagnetic change due to non-uniform magnetization in the Earth's crust - two-dimensional case studies, J. Geomagn. Geoelectr., 42, 607-619.

Rikitake, T., Y. Honkura, H. Tanaka, N. Ohshiman Y. Sasay, Y. IshiKaWa, S. Koyama, M. KaWAmura and K. OHCHI (1980): Changes in the geomagnetic field associated with earthquakes in the Izu Peninsula, Japan, $J$. Geomagn. Geoelectr., 32 (12), 721-739.

SASAI, Y. (1983): A surface integral representation of the tectonomagnetic field based on the linear piezomagnetic effect, Bull. Earthquake Res. Inst., Univ. Tokyo, 58, 763-785.

Shapiro, V., M. Muminov, T. Khadzhyev and K. AbdulLABEKOV (1994): Magnetic field variations of crustal origin measured in the Fergana Valley of Usbekistan, reflecting seismotectonic dynamics, in Electromagnetic Phenomena Related to Earthquake Prediction, edited by M. HAYAKAWA and Y. FujINAWA (Terra Scientific Publishing Co., Tokyo), 43-49.

Sobolev, O.A. and P.G. DJADKOv (2003): Software for calculation of tectonomagnetic anomalies induced by piezo- 
magnetic effect, in The XXIII General Assembly of the IUGG, Japan, Abstract A.22.

StACEY, F.D. (1964): The seismomagnetic effect, Pure Appl. Geophys., 58 (2), 5-22.

ZlotNicki, J. and F.H. CORNET (1986): A numerical model of earthquake-induced piezomagnetic anomalies, $J$. Geophys. Res., 91 (B1), 709-718.

Zlotnicki, J. and J.L. Le MouËL (1990): Possible electrokinetic origin of large magnetic variations at La Fournaise volcano, Nature, 343 (6259), 633-636. 